\title{
Determination of Pear Cultivars (Pyrus communis L.) Based on Colour Change Levels by Using Data Mining
}

\author{
Dilara Gerdan ${ }^{1, a}$, Abdullah Beyaz ${ }^{1, b, *}$, Mustafa Vatandaş ${ }^{1, c}$ \\ ${ }^{1}$ Department of Agricultural Machinery and Technologies Engineering, Faculty of Agriculture, Ankara University, 06110 Ankara, Turkey \\ *Corresponding author
}

\section{A R T I C L I N F O A B S T R A C T}

\section{Research Article}

Colour is an essential parameter at product quality control stages, and finally, it is necessary for the consumer marketing decision. It is possible to damage the products during the process from collection to storage. Also, it is a well-known condition, cold environmental conditions protect fruits from

Received : 03/01/2020

Accepted : 03/03/2020 deformations negative effects, but most of the time, most of the consumers keep the fruits at room temperature in open packs during the consumption process. Also, this condition affects the product storage time. In this study, it is aimed that to determine the behaviours of the fruits in room temperature and humidity conditions. For this aim the colour change of the damaged pears were determined, in another term, colour change value from red to green and yellow to blue at the damaged pears were determined with lightness values by using image analysis technique and analysed with data mining

Keywords:

Pear

Image processing

Colour change

Data mining

Meta-learning methods. For this purpose, 100 "Akça" pear and 100 "Deveci" local pear cultivar used for experiments. Fruits were equally damaged by using a pendulum mechanism. The damaged fruits were kept at room temperature. Colour change areas on fruits were evaluated with X-rite Ci60 spectrophotometer, and the hardness of fruits was measured by using a fruit penetrometer. The colour $(L, a, b)$ and $\Delta \mathrm{E}$ values were analysed for the fruit cultivars. The relationship between fruit hardness and colour change were also demonstrated. The predictions were done supervised machine learning algorithms (Decision Tree and Neural Networks with Meta-Learning Techniques; Majority Voting and Random Forest) by using KNIME Analytics software. The classifier performance (accuracy, error, F-Measure, Cohen's Kappa, recall, precision, true positive (TP), false positive (FP), true negative (TN), false negative (FN) values were given at the conclusion section of the research. The best prediction were found at the Majority Voting method (MAVL) $98.458 \%$ success given with $70 \%$ partitioning.

dgerdan@ankara.edu.tr vatandas@agri.ankara.edu.tr
https://orcid.org/0000-0002-2705-299X D htps://orcid.org/0000-0003-3235-042X b@abeyaz@ankara.edu.tr

https://orcid.org/0000-0002-7329-1318

\section{Introduction}

Adequate and high-quality agricultural production has become a necessity to meet the needs of the increasing world population. Trade of agricultural products can be produce as raw, semi-finished, or processed to meet the demands. Regardless of the other countries, our country is not able to offer some desired quality products to the market. As a result of this condition, the problem decreases to chance of competition for export. Many developed countries bring certain quality standards as a prerequisite for import products. The concept of product quality includes the characteristics of odour, taste, cleanliness, and exterior appearance. The transmission of products to the market especially must be undamaged and robust, and this condition is a factor increasing the chance of competition. Preventing product losses occurring at various stages within the chain extending from producer to consumer is necessary to protect the limited agricultural resources while increasing the foreign exchange revenues by introducing the surplus products to the foreign market. In this regard, the development of harvesting, transportation, cleaning, classification and storage conditions of agricultural products and packaging will play an important role in increasing our exports to the world markets. (Yurtlu, 2003; Beyaz, 2008).

A lot of studies were done in the literature to achieve this aim. For example, Beyaz et al. (2011) determined colour change on pears with colour parameters. Their experiment results showed that " $L$ values" were more critical than $a$ and $b$ values. Wu et al. (2012) worked on the measurement of the colour distribution in the salmon fillet. They said that, used multiple linear regression (MLR) models with effective predictive wavelengths, which resulted in correlation coefficients reliable and rapid alternative to traditional colorimeter for measuring the colour of salmon fillet. Küçükönder et al. (2015) studied on the colour maturity of tomato with K-Star, Random Forest, and Decision Tree (C4.5) classification algorithms. According to their results, 
K-Star instance-based algorithm was found as a better classifier compared to the others. Taghadomi-Saberi et al. (2015) determined of cherry colour parameters with an artificial neural network. They stressed that evaluation of $L^{*}$, $a^{*}$, and $b^{*}$ values showed the possibility of reliable use of this system compared with a chromameter. Demir (2018) worked on application of data mining and adaptive neurofuzzy structure to predict colour parameters of walnuts (Juglans regia L.) and he stressed that the equations which are obtained from their measurements can be used as a viable alternative instead of equations that vary depending on whether $a^{*}$ and $b^{*}$ are negative or positive. Additionally, Demir et al. (2018) studied on data mining approach for the prediction of fruit colour properties. They have applied laws algorithm to each cluster and 7 different prediction rules were obtained by them from $C I, h^{*}$ and $C^{*}$ parameters. They express that $\mathrm{R}^{2}$ values of the rules were compared and the rules with the most accurate outcomes were identified.

In this research, it is aimed to predict colour changes at two different pear cultivars "Akça" and "Deveci" pears as storage quality parameter. It is a well-known condition, cold environmental conditions protect fruits from deformations negative effects, but most of the time, most of the consumers keep the fruits at room temperature in open packs during the consumption process. Also, this condition affects the product storage time. In this study, it is aimed that to determine the behaviours of the fruits in room temperature and humidity conditions. The predictions were done supervised machine learning algorithms that are Decision Tree and Neural Networks with Meta-Learning Techniques; Majority Voting and Random Forest by using KNIME Analytics software. Also, the classifier performance (accuracy, error, F-Measure, Cohen's Kappa, recall, precision, true positive, false positive, true negative, false negative) values were given at the conclusion section of the research.

\section{Material and Methods}

\section{Data Collection}

The pears were obtained from a local market, because of this reason the measurement process was applied 1 week later after the harvest process. A total of 200 pears were taken from local market that are 100 Akça pears, and 100 Deveci pears, and they were damaged from different sides of their surfaces. Some biological material properties of the pears can be seen in Table 1. Fruits were numbered from the stem pits. Then, they were kept at room temperature, and measurements were done day by day until full decay (for five days). A database of 4000 data was obtained from the readings which were taken from damaged pear samples for five days (Figure 1). The database was composed of four numerical characteristics of $L, a, b$ and $\Delta \mathrm{E}$ colour values.

\section{Spectrophotometer and Penetrometer Measurements}

In this research, the X-rite $\mathrm{Ci} 60$ model portable spectrophotometer was used to obtain colour data from damaged fruits (Figure 2). Specifications of the X-rite Ci60 model portable spectrophotometer can be seen in Table 2.

Table 1. Some biological material properties of pears

\begin{tabular}{l|cc}
\hline \multicolumn{1}{c}{ Biological Material Properties } & Akça Pear (Average) & Deveci Pear (Average) \\
\hline Width & $40 \mathrm{~mm}$ & $78 \mathrm{~mm}$ \\
Height & $60 \mathrm{~mm}$ & $79 \mathrm{~mm}$ \\
Weight & $44 \mathrm{gr}$ & $225 \mathrm{gr}$ \\
Hardness & $4 \mathrm{~kg} / \mathrm{cm}^{2}$ & $16 \mathrm{~kg} / \mathrm{cm}^{2}$ \\
\hline
\end{tabular}

Table 2. Specifications of the X-rite Ci60 model portable spectrophotometer (Anonymous, 2020)

\begin{tabular}{|c|c|}
\hline Short Term Repeatability - White & $10 \Delta \mathrm{E}^{*} \mathrm{ab}$ on white ceramic \\
\hline Measurement Geometry & $\mathrm{d} / 8^{\circ}$ \\
\hline Inter-Instrument Agreement & $0.40 \Delta \mathrm{E}^{*} \mathrm{ab}$ avg. \\
\hline Illumination Spot Size & $14 \mathrm{~mm}$ \\
\hline Light Source & Gas-filled tungsten lamp \\
\hline Measurement Spot & $8 \mathrm{~mm}$ \\
\hline Measurement Time & $\approx 2$ seconds \\
\hline Photometric Resolution & $0.01 \%$ \\
\hline Spectral Analyser & Blue-enhanced silicon photodiodes \\
\hline Spectral Interval & $10 \mathrm{~nm}$ \\
\hline Spectral Range & $400 \mathrm{~nm}-700 \mathrm{~nm}$ \\
\hline Spectral Reporting & $10 \mathrm{~nm}$ \\
\hline Colour Differences & $\begin{array}{l}{[\sqrt{ } / \mathrm{X}], \Delta \mathrm{ecmc}, \Delta \mathrm{lab}, \Delta \mathrm{E} 00, \Delta \text { reflectance, } \Delta \mathrm{E} 94, \Delta \mathrm{XYZ}, \Delta \mathrm{L}^{*} \mathrm{a}^{*} \mathrm{~b}^{*}, \Delta \mathrm{Yxy},} \\
\Delta \mathrm{L}^{*} \mathrm{C}^{*} \mathrm{~h}^{\circ}, \Delta \mathrm{L}^{*} \mathrm{u}^{*} \mathrm{~V}^{*}, \text { Verbal Difference }\end{array}$ \\
\hline Colour Spaces & Lab, L*a*b*, Reflectance, $\mathrm{L}^{*} \mathrm{C}^{*} \mathrm{~h}^{\circ}$, Munsell Notation, XYZ, Yxy, L*u* $\mathrm{v}^{*}$ \\
\hline Illuminates & $\mathrm{A}, \mathrm{C}, \mathrm{D} 50, \mathrm{D} 65, \mathrm{~F} 2, \mathrm{~F} 7, \mathrm{~F} 11 \& \mathrm{~F} 12$ \\
\hline Standard Indices & $\begin{array}{l}{[\sqrt{ } / \mathrm{X}] \text {, YI1925, WI Taube, } \Delta \text { WI73, Reflectance, WI98, MI, } \Delta \text { reflectance, } \Delta \text { WI }} \\
\text { Berger, WI73, MI6172, } \Delta \text { YI98, } \Delta \text { WI Hunter, GrayScale, WI Berger, Gloss, } \\
\Delta \text { YI73, } \Delta \text { WI Stensby, YI98, WI Hunter, } \Delta \text { YI1925, } \Delta \text { WI Taube, YI73, WI } \\
\text { Stensby, } \Delta \text { WI98, Averaging, } 555 \text { Shade Sort }\end{array}$ \\
\hline Sample/Measurement & 4000 \\
\hline Calibration & White and Zero \\
\hline
\end{tabular}




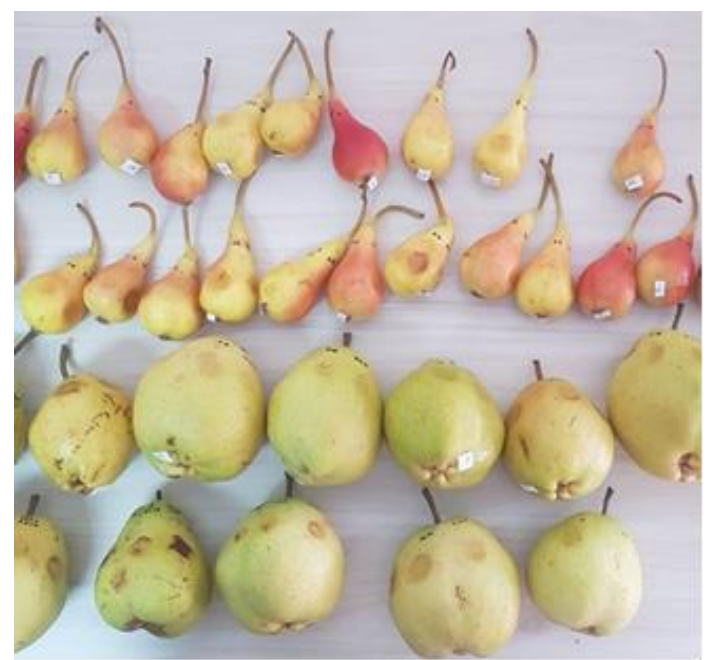

Figure 1. Damaged Akça and Deveci pear samples

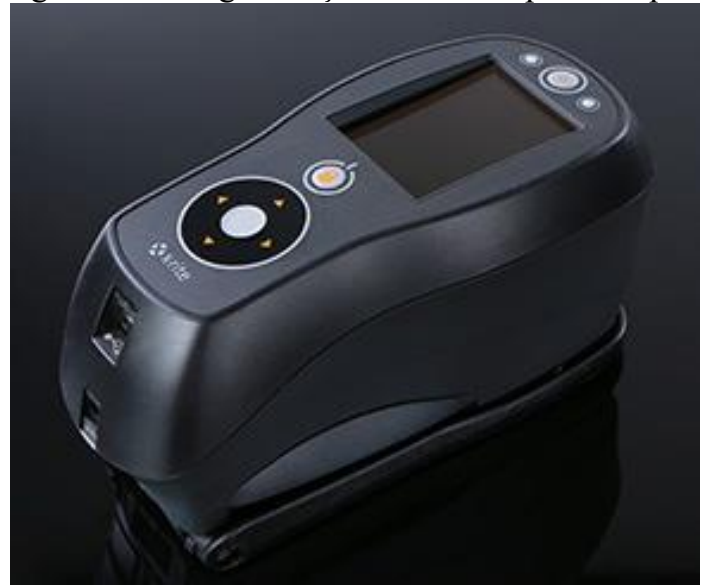

Figure 2. X-rite Ci60 model portable spectrophotometer used in the study (Anonymous, 2019)

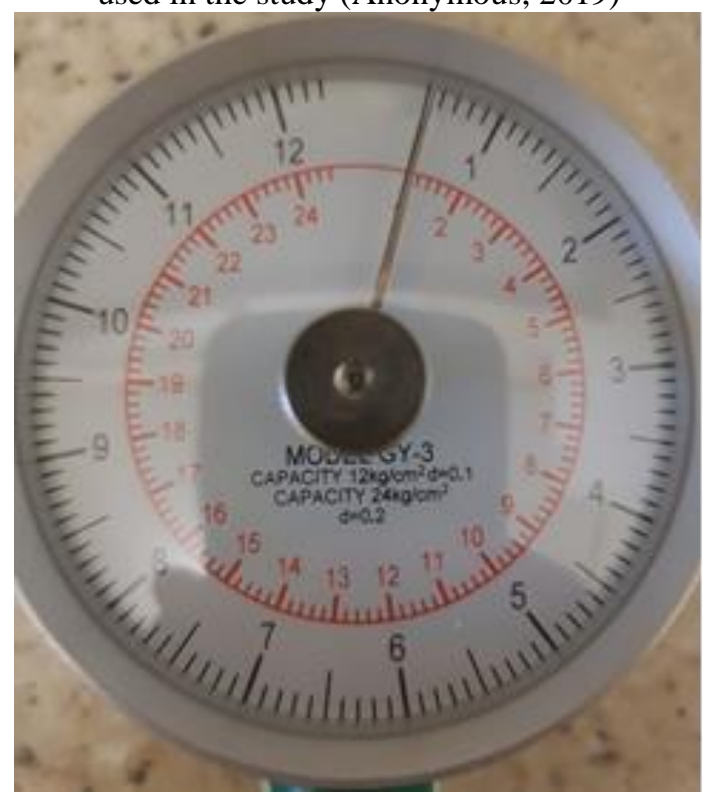

Figure 3. Fruit hardness hand penetrometer

The spectrophotometer used to determine the colour values in the wavelength range of $400-700 \mathrm{~nm}$. In this study, the measurements of the desired colour space $(L, a$, $b)$ were done, also Euclidian distance between two samples in the Lab colour space $(\Delta \mathrm{E})$ were measured as the colour difference of the pears. The following formula calculates the $\Delta \mathrm{E}$ value:

$$
\Delta \mathrm{E}=\left[\left(\Delta \mathrm{L}^{2}\right)+\left(\Delta \mathrm{a}^{2}\right)+\left(\Delta \mathrm{b}^{2}\right)\right]^{1 / 2}
$$

In this equation:

$\Delta \mathrm{E}$ : Change in colour value,

$\Delta \mathrm{L}$ : Brightness value

$\Delta \mathrm{a}:$ Colour change value from red to green,

$\Delta \mathrm{b} \quad$ : Colour change value from yellow to blue (Beyaz et al. 2011).

Fruit hardness values were determined by using a hand penetrometer (Figure 3).

\section{Decision Tree Algorithms}

One of the standard algorithms is Decision Trees, which are used in data mining methods. Decision Trees aim to show object specifications, which predicts the value of a traced data by learning basic classification rules that are obtained from objects. Each node in a Decision Tree inserts a spec of an example that can be classified. Also, there are a lot of algorithms that are used to determine essential branches at collected data. Root, node, and branching criteria are the vital points of these algorithms (Silahtaroğlu, 2016, Köse, 2018).

Classification methods in decision trees are divided into two methods.

These are;

- Entropy-Based Algorithms (ID3 Algorithm, C4.5 Algorithm, etc.)

- Classification and Regression Trees (CART) (Towing Algorithm, Gini Algorithm, Random Forest Algorithm, etc.).

The C4.5 tree is an improved version of the ID3 tree. It is an algorithm based on entropy and information gain the same as the ID3 algorithm. Unlike the ID3 algorithm, pruning is performed in this algorithm (Köse, 2018). The following equation calculates entropy:

$$
\mathrm{H}(\mathrm{S})=\sum_{\mathrm{t}=1}^{\mathrm{n}} \rho \mathrm{i} \times \log _{2}(\rho \mathrm{i})
$$

$$
\begin{array}{ll}
\mathrm{H} & \text { : Entropy, } \\
\mathrm{S} & \text { : Source, } \\
\mathrm{p} & \text { : Probability (Silahtaroğlu, 2016). }
\end{array}
$$

Gain information is obtained by calculating the differences between the weighted sums of the entropies of each sub-section (Silahtaroğlu, 2016). The following equation calculates the gain information:

$$
\begin{aligned}
& \mathrm{D}=\mathrm{H}(\mathrm{D})-\sum_{\mathrm{t}=1}^{\mathrm{n}} \mathrm{P}\left(\mathrm{D}_{\mathrm{i}}\right) \mathrm{H}\left(\mathrm{D}_{\mathrm{i}}\right) \\
& \mathrm{D} \quad \text { : Gain information, } \\
& \mathrm{H} \quad \text { : Entropy, } \\
& \mathrm{p} \quad \text { : Probability (Silahtaroğlu, 2016). }
\end{aligned}
$$

In this study, the gain ratio was selected as a quality measure, and Minimum Description Length (MDL) was selected as the pruning method in Decision Tree.

\section{Neural Network Algorithm}

Neural networks are complex algorithms that work like a human brain. It works like a human's nervous system. The network system runs according to the complex data 
combination and transmission between nerve cell lines. Each combination has a critical weight value. The process has different steps between layers as the input layer, the hidden layers, and the output layer. The info is obtained from the input layer then transmit to the hidden layer for classification according to the critical weight value of the network finally, send to the output layer (Öztemel, 2012). In this study, KNIME data mining software artificial neural network structure and algorithm was used.

\section{Majority Voting Techniques}

Meta-learning is an advanced technique in data mining and meta-learning aims to learn from the predictions of the classifiers on a current validation data set. At the end of the classification, the meta-classifier works to train from the standard validation data set (Prodromidis et al., 2000). For this aim, Random Forest and Majority Voting Techniques were selected. This method is known as the form of voting by the majority according to the estimates obtained from the algorithms used. If there is equality in the algorithms used, the results of the algorithms are also examined. It is considered to be one of the simplest and most effective methods (Şeker and Erdogan, 2018). This method was only applied to machine learning algorithms.

\section{Random Forest Algorithm}

Leo Biean developed the Random Forest algorithm. The method runs according to complex answers of different trees finally gives a decision. Random Forest is an ensemble learning method in meta-learning. The Random Forest is the final version of the CART algorithm. It is one of the standard meta-learning methods that gives fast and straightforward. It decides randomly selected values and specifications then built different Decision Trees finally gives the average of results. (Mitchell, 2011). It is an algorithm that aims to increase the classification value by producing more than one decision tree during the classification process.

\section{Data Analysis}

The fruits kept at room temperature during the measurements done for 5 days. Because most of the time consumers keep the agricultural products at room temperature in open packs during the consumption process. Fruits are kept in the $25^{\circ} \mathrm{C}$ temperature and $40 \%$ humidity as the environmental conditions. Also, this condition affects the product storage time. Four digital reading was received as the fruit colour quality ( $L, a$ and $b$ colour channels and $\Delta \mathrm{E}$ values), a database that was created 4000 objects. In the database, the class assignments of the fruit qualities were determined. Using the KNIME Analytics Platform software, data were identified using descriptive statistical methods and then analysed by classification techniques used in data mining. In the classification the labelled values were tried to be estimated, the Majority Voting and Random Forest methods were used. $70 \%$ training $-30 \%$ test and $80 \%$ training - 20\% test selected as partitioned methods. In the relevant part of the study, comparison performances and confusion matrix were given in the tables.

\section{Results and Discussion}

The study results showed that that the best prediction were done by the Majority Voting method (MAVL) with $98,458 \%$ success given by $70 \%$ partitioning. Following, the Random Forest algorithm showed $94 \%$ success. On the first day, the fruit colours were read with the help of a spectrometer without any damage. Therefore, Delta-E values for the first day were given as zero (0). The relationship between fruit hardness and colour change was demonstrated in Table 3. In Table 3, it is seen that first day two pear varieties have colour changes but as soft pear variety, Akça pear shows more colour changes in the other days. It was correlated with the average Delta-E $(\Delta \mathrm{E})$ values obtained from fruits. In addition to fruit hardness, Red colour change of the fruits also played a vital role, and orange shells showed less browning while yellow and green shells showed more browning. The confusion matrix and accuracy criteria of used algorithms were given in Table 4 and Table 5.

With a parallel understanding in the literature, Rajeswari and Arunesh (2016) analysed soil by using soil colour, texture, PH, EC, etc. parameters. For these purposes, they were used JRip, J48, and Naive Bayes algorithms. According to their study result, the success of JRip algorithms 98.18\%, for J48 97.27\% and Naïve Bayes $86.36 \%$. Zareiforoush et al. (2016) classified milled rice grains using computer vision and artificial neural networks, support vector machines, decision trees, and Bayesian Networks. The experiment showed that the highest classification accuracy is $98.72 \%$. Next, support vector machine with Universal Pearson VII kernel function (98.48\%), decision tree with REP algorithm (97.50\%), and Bayesian Network with Hill Climber search algorithm (96.89\%) had the higher accuracy, respectively. VirgenNavarro et al. (2016) monitored coffee bean colour using a neuro-fuzzy model based on digital images. The performance of the neuro-fuzzy model resulted better compared to conventional methods obtaining a coefficient of determination $>0.98$.

Sabanc1 et al. (2017) classified wheat grains using an artificial neural network according to dimensions, colours, and textures parameters of 100 bread and 100 durum wheat grains. They said that the ANN model is trained with 180 grains and its accuracy tested with 20 grains for a total of 200 wheat grains. Tang et al. (2017) identified weed based on K-means and convolutional neural networks. The experimental results were found that K-means pre-training achieved $92.89 \%$ accuracy. Beyaz et al. (2017) identification some Spanish olive cultivars using length, width, and colour data of olives.

Table 3. The relationship between fruit hardness and colour change

\begin{tabular}{l|cccccc}
\hline Cultivars & Fruit Hardness & $\Delta \mathrm{E}(1$. Day) & $\Delta \mathrm{E}(2$. Day) & $\Delta \mathrm{E}(3$. Day) & $\Delta \mathrm{E}(4$. Day) & $\Delta \mathrm{E}(5$. Day) \\
\hline Akça Pear & $4 \mathrm{~kg} / \mathrm{cm}^{2}$ & 0 & 9.784816 & 3.86616 & 3.63344 & 3.39506 \\
\hline Deveci Pear & $16 \mathrm{~kg} / \mathrm{cm}^{2}$ & 0 & 14.21650 & 2.58295 & 2.72176 & 2.51253 \\
\hline
\end{tabular}


Table 4. Confusion matrix and accuracy criteria of used algorithms (70\% training, 30\% test)

\begin{tabular}{|c|c|c|c|c|c|c|c|}
\hline Classifier & Confusion Matrix & Akça Pear & Deveci Pear & Accuracy (\%) & Error $(\%)$ & $\mathrm{F}$ & Cohen's Kappa \\
\hline \multirow{5}{*}{ DT } & Akça Pear & 133 & 20 & 89.333 & 10.667 & 0.893 & 0.787 \\
\hline & Deveci Pear & 12 & 135 & & & 0.894 & \\
\hline & Accuracy Criteria & Recall & Precision & $\mathrm{TP}$ & FP & TN & FN \\
\hline & Akça Pear & 0.869 & 0.917 & 133 & 12 & 135 & 20 \\
\hline & Deveci Pear & 0.918 & 0.871 & 135 & 20 & 133 & 12 \\
\hline \multirow{5}{*}{ ANN } & Akça Pear & 140 & 13 & 90.667 & 9.333 & 0.909 & 0.813 \\
\hline & Deveci Pear & 15 & 132 & & & 0.904 & \\
\hline & Accuracy Criteria & Recall & Precision & $\mathrm{TP}$ & FP & $\mathrm{TN}$ & FN \\
\hline & Akça Pear & 0.915 & 0.903 & 140 & 15 & 132 & 13 \\
\hline & Deveci Pear & 0.898 & 0.91 & 132 & 13 & 140 & 15 \\
\hline \multirow{5}{*}{$\mathrm{RF}$} & Akça Pear & 140 & 13 & 92.667 & 7.333 & 0.927 & 0.853 \\
\hline & Deveci Pear & 9 & 138 & & & 0.926 & \\
\hline & Accuracy Criteria & Recall & Precision & $\mathrm{TP}$ & FP & $\mathrm{TN}$ & FN \\
\hline & Akça Pear & 0.915 & 0.94 & 140 & 9 & 138 & 13 \\
\hline & Deveci Pear & 0.939 & 0.914 & 138 & 13 & 140 & 9 \\
\hline \multirow{5}{*}{ MAVL } & Akça Pear & 21876 & 599 & 98.458 & 1.542 & 0.984 & 0.969 \\
\hline & Deveci Pear & 94 & 22381 & & & 0.985 & \\
\hline & Accuracy Criteria & Recall & Precision & $\mathrm{TP}$ & FP & $\mathrm{TN}$ & FN \\
\hline & Akça Pear & 0.973 & 0.996 & 21876 & 94 & 22381 & 599 \\
\hline & Deveci Pear & 0.996 & 0.973 & 22381 & 599 & 21876 & 94 \\
\hline
\end{tabular}

Table 5. Confusion matrix and accuracy criteria of used algorithms (80\% training, 20\% test)

\begin{tabular}{|c|c|c|c|c|c|c|c|}
\hline Classifier & Confusion Matrix & Akça Pear & Deveci Pear & Accuracy (\%) & Error $(\%)$ & $\mathrm{F}$ & Cohen's Kappa \\
\hline \multirow{5}{*}{ DT } & Akça Pear & 71 & 21 & \multirow[t]{2}{*}{84} & \multirow[t]{2}{*}{16} & 0.816 & \multirow[t]{2}{*}{0.675} \\
\hline & Deveci Pear & 11 & 97 & & & 0.858 & \\
\hline & Accuracy Criteria & Recall & Precision & $\mathrm{TP}$ & FP & $\mathrm{TN}$ & $\mathrm{FN}$ \\
\hline & Akça Pear & 0.772 & 0.866 & 71 & 11 & 97 & 21 \\
\hline & Deveci Pear & 0.898 & 0.822 & 97 & 21 & 71 & 11 \\
\hline \multirow{5}{*}{ ANN } & Akça Pear & 84 & 8 & \multirow[t]{2}{*}{88} & \multirow[t]{2}{*}{12} & 0.875 & \multirow[t]{2}{*}{0.76} \\
\hline & Deveci Pear & 16 & 92 & & & 0.885 & \\
\hline & Accuracy Criteria & Recall & Precision & $\mathrm{TP}$ & FP & TN & $\mathrm{FN}$ \\
\hline & Akça Pear & 0.913 & 0.84 & 84 & 16 & 92 & 8 \\
\hline & Deveci Pear & 0.852 & 0.92 & 92 & 8 & 84 & 16 \\
\hline \multirow{5}{*}{$\mathrm{RF}$} & Akça Pear & 85 & 7 & \multirow[t]{2}{*}{90.5} & \multirow[t]{2}{*}{9.5} & 0.899 & \multirow[t]{2}{*}{0.81} \\
\hline & Deveci Pear & 12 & 96 & & & 0.91 & \\
\hline & Accuracy Criteria & Recall & Precision & $\mathrm{TP}$ & FP & $\mathrm{TN}$ & $\mathrm{FN}$ \\
\hline & Akça Pear & 0.924 & 0.876 & 85 & 12 & 96 & 7 \\
\hline & Deveci Pear & 0.889 & 0.932 & 96 & 7 & 85 & 12 \\
\hline \multirow{5}{*}{ MAVL } & Akça Pear & 7890 & 310 & 98.34 & 1.66 & 0.979 & 0.966 \\
\hline & Deveci Pear & 22 & 11778 & & & 0.986 & \\
\hline & Accuracy Criteria & Recall & Precision & $\mathrm{TP}$ & FP & $\mathrm{TN}$ & FN \\
\hline & Akça Pear & 0.962 & 0.997 & 7890 & 22 & 11778 & 310 \\
\hline & Deveci Pear & 0.998 & 0.974 & 11778 & 310 & 7890 & 22 \\
\hline
\end{tabular}

The cultivars were identified as $90 \%$ with Artificial Neural Networks. About this issue in literature Demir (2018) worked on application of data mining and adaptive neuro-fuzzy structure to predict colour parameters of walnuts (Juglans regia L.) and he stresses that root mean square error values of the adaptive neuro-fuzzy-based approach were respectively identified as 0.02 for Bilecik, 0.01 for Fernette, 0.02 for Fernor, 0.01 for Kaman-1, 0.01 for Maraş-12, 0.01 for Maraş-18, 0.01 for Sunland, 0.01 for Şen-2, 0.01 for Yalova-1, and 0.01 for Yalova-3 walnuts. Additionally, Demir et al. (2018) studied on data mining approach for the prediction of fruit colour properties. They have applied laws algorithm to each cluster and 7 different prediction rules were obtained by them from $C I, h^{*}$ and $C^{*}$ parameters. They express that $\mathrm{R}^{2}$ values of the rules were change between $0.72-0.99 \%$.

\section{Conclusion}

Determination of the oxidation areas due to the damage in pears is the feature to be considered in the design of harvesting, classification, packaging, transportation, and transmission machines. The image analysis technique is an indispensable method, especially in the design of machines that classify the fruits according to their quality. The data results provide us a chance to estimate the skin colour changes at bruised areas with data mining methods. This study shows that the image analysis techniques and data mining can be used to determine the colour values of pears or similar products. It is also thought to include results that can shed light on the studies in this area. 


\section{References}

Anonymous, 2019. X-Rite Ci60. Available from: http://www.3nhcolorimeter.com/Spectrophotometer/118.htm 1. (27.06.2019).

Anonymous, 2020. Specifications of The X-Rite Ci60 Portable Spectrophotometer. Available from: https://www.xrite.com/ categories/portable- spectrophotometers/ci60. (01.03.2020)

Beyaz A, Özkaya MT, İçen D. 2017. Identification of Some Spanish Olive Cultivars Using Image Processing Techniques, Sci. Hortic., 225: 286-292.

Beyaz A, Öztürk R, Acar Aİ, Turker U. 2011. Determination of Color change on Quinces (Cydonia oblongo) with Color Analysis. Journal of Agricultural Machinery Science, 7 (4): 411-414.

Beyaz A. 2008. Determining of Mechanical Damage of Apples by Using Image Analyse Technique. Master Thesis, Ankara University, Graduate School of Natural and Applied Sciences, Department of Agricultural Machinery, Ankara.

Demir B, Gürbüz F, Eski I, Kus ZA. 2018. Data Mining Approach for Prediction of Fruit Color Properties. Atatürk University Journal of the Agricultural Faculty, 49 (1): 37-43.

Demir B. 2018. Application of Data Mining and Adaptive NeuroFuzzy Structure to Predict Color Parameters of Walnuts (Juglans regia L.). Turk J Agric For., 42 (3): 216-225.

Köse İ. 2018. Veri Madenciliği Teori Uygulama ve Felsefesi. Papatya Yayıncılık Eğitim, 280 s., İstanbul, Türkiye.

Küçükönder H, Vursavuş KK, Üçkardeş F. 2015 Determining the Effect of Some Mechanical Properties on Color Maturity of Tomato With K-Star, Random Forest and Decision Tree (C4.5) Classification Algorithms. TURJAF, 3 (5): 300-306.

Mitchell MV. 2011. Bias of the Random Forest Out-of-Bag (OOB) Error for Certain Input Parameters. OJS, 2011 (1): 205-211, DOI:10.4236/ojs.2011.13024.2011.

Öztemel E. 2012. Artificial Neural Networks. 3rd Edition, Papatya Publishing, Istanbul.

Prodromidis A, Chan P, Stolfo S. 2000. Meta-learning in Distributed Data Mining Systems: Issues and Approaches. In Advances in Distributed and Parallel Knowledge Discovery, H. Kargupta and P. Chan (editors), AAAI/MIT Press.
Rajeswari V, Arunesh K. 2016. Analysing Soil Data using Data Mining Classification Techniques. Indian J Sci Technol, 9 (19), DOI: $10.17485 / \mathrm{ijst} / 2016 / \mathrm{v} 9 \mathrm{i} 19 / 93873$.

Sabanc1 K, Kayabasi A, Toktas A. 2017. Computer Vision- Based Method for Classification of Wheat Grains Using Artificial Neural Network. J. Sci. Food Agric., 97(8): 2588-2593.

Şeker ŞE, Erdogan D. 2018. KNIME İle Uçtan Uca Veri Bilimi. 1. Basım, 440 s., Demet Erdoğan Yayınevi.

Silahtaroğlu G. 2016. Data Mining Concepts and Algorithms. 3. Printing, 304 p., Papatya Publishing, Istanbul.

Taghadomi-Saberi S, Omid M, Emam-Djomeh Z, FarajiMahyari Kh. 2015. Determination of Cherry Color Parameters during Ripening by Artificial Neural Network Assisted Image Processing Technique. J Agr Sci Tech. 17(3): 589-600.

Tang J, Wang D, Zhang Z, He L, Xin J, Xu Y. 2017. Weed Identification Based on K-Means Feature Learning Combined with Convolutional Neural Network. Comput Electron Agric, 135: 63-70.

Virgen-Navarro L, Herrera-Lopez E J, Corona-Gonzales RI, Arriola-Guevara E, Guatema-Morales GM. 2016. NeuroFuzzy Model Based on Digital Images for The Monitoring of Coffee Bean Color During Roasting in A Spouted Bed. Expert Syst. Appl., 54: 162-169.

Wu D, Sun DW, HE Y. 2012. Application of Long-Wave Near Infrared Hyperspectral Imaging for Measurement of Color Distribution in Salmon Fillet. Innov Food Sci Emerg, 16: 361-372.

Yurtlu YB. 2003. Determination of Some Mechanical Properties and Susceptibility to Bruising Damage of Fruits and Vegetables. Ph.D. Thesis, Ankara University, Graduate School of Natural and Applied Sciences, Department of Agricultural Machinery, Ankara.

Zareiforoush H, Minaei S, Alizadeh MR, Banakar A. 2016. Qualitative Classification of Milled Rice Grains Using Computer Vision and Metaheuristic Techniques. Int. J. Food Sci., 53(1): 118-131. ' 